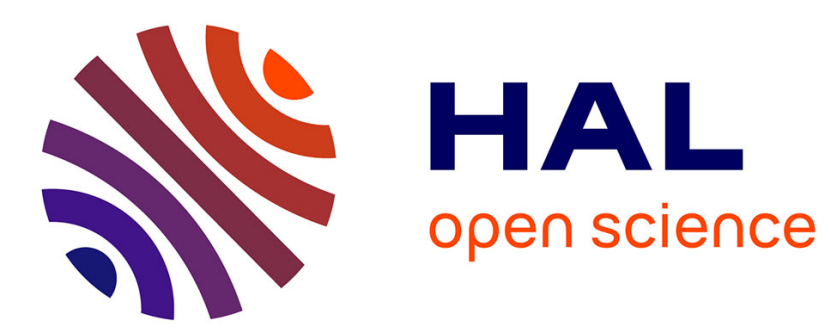

\title{
Rhétorique du don: patronage, performance poétique et rétribution dans les premières décennies du califat abbasside
}

\author{
Mathias Hoorelbeke
}

\section{- To cite this version:}

Mathias Hoorelbeke. Rhétorique du don : patronage, performance poétique et rétribution dans les premières décennies du califat abbasside. Arabica, 2015, 62 (1), pp.99-127. 10.1163/15700585-12341337 . halshs-01132846

\author{
HAL Id: halshs-01132846 \\ https://shs.hal.science/halshs-01132846
}

Submitted on 18 Mar 2015

HAL is a multi-disciplinary open access archive for the deposit and dissemination of scientific research documents, whether they are published or not. The documents may come from teaching and research institutions in France or abroad, or from public or private research centers.
L'archive ouverte pluridisciplinaire HAL, est destinée au dépôt et à la diffusion de documents scientifiques de niveau recherche, publiés ou non, émanant des établissements d'enseignement et de recherche français ou étrangers, des laboratoires publics ou privés. 


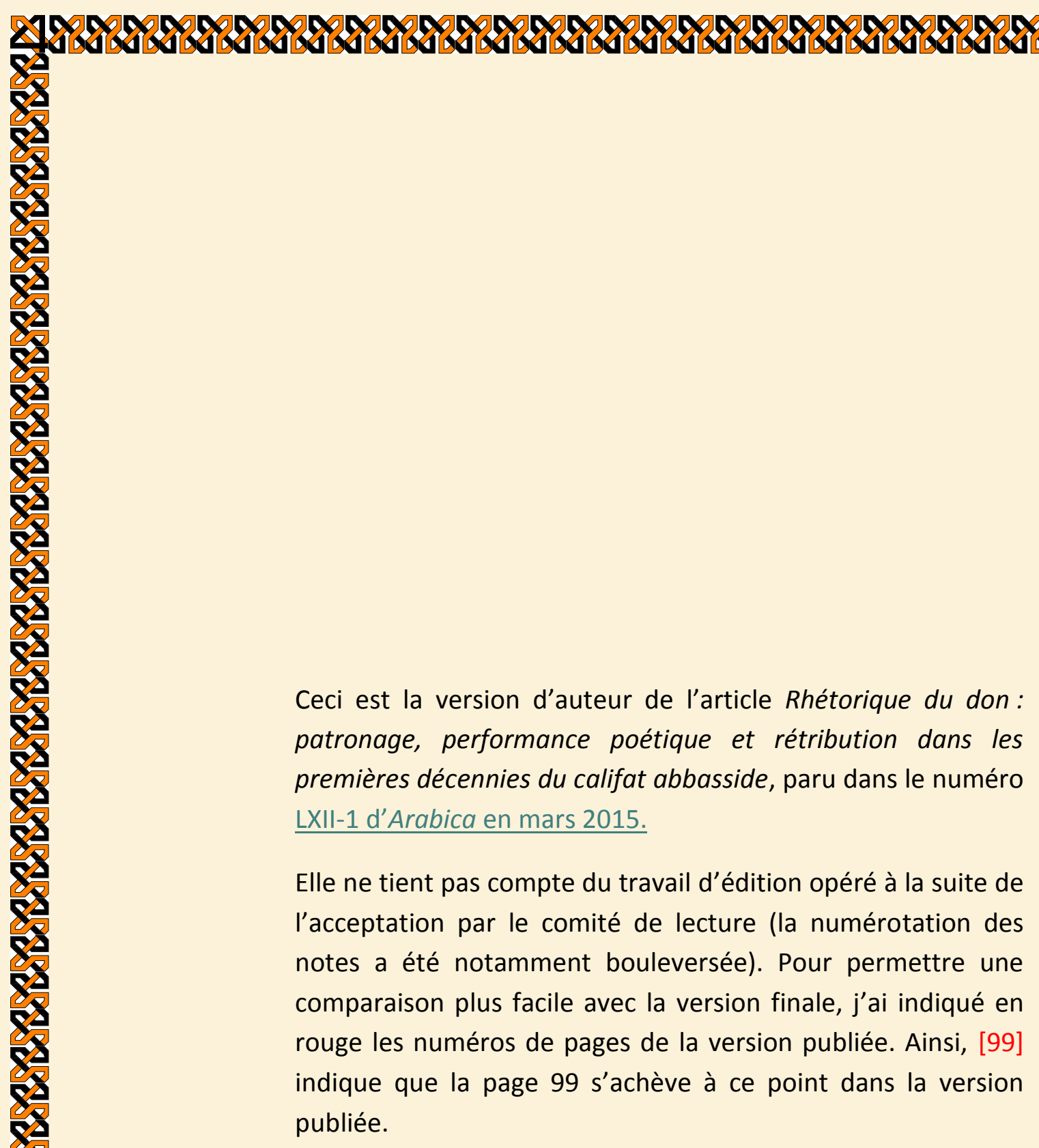

Mathias Hoorelbeke 


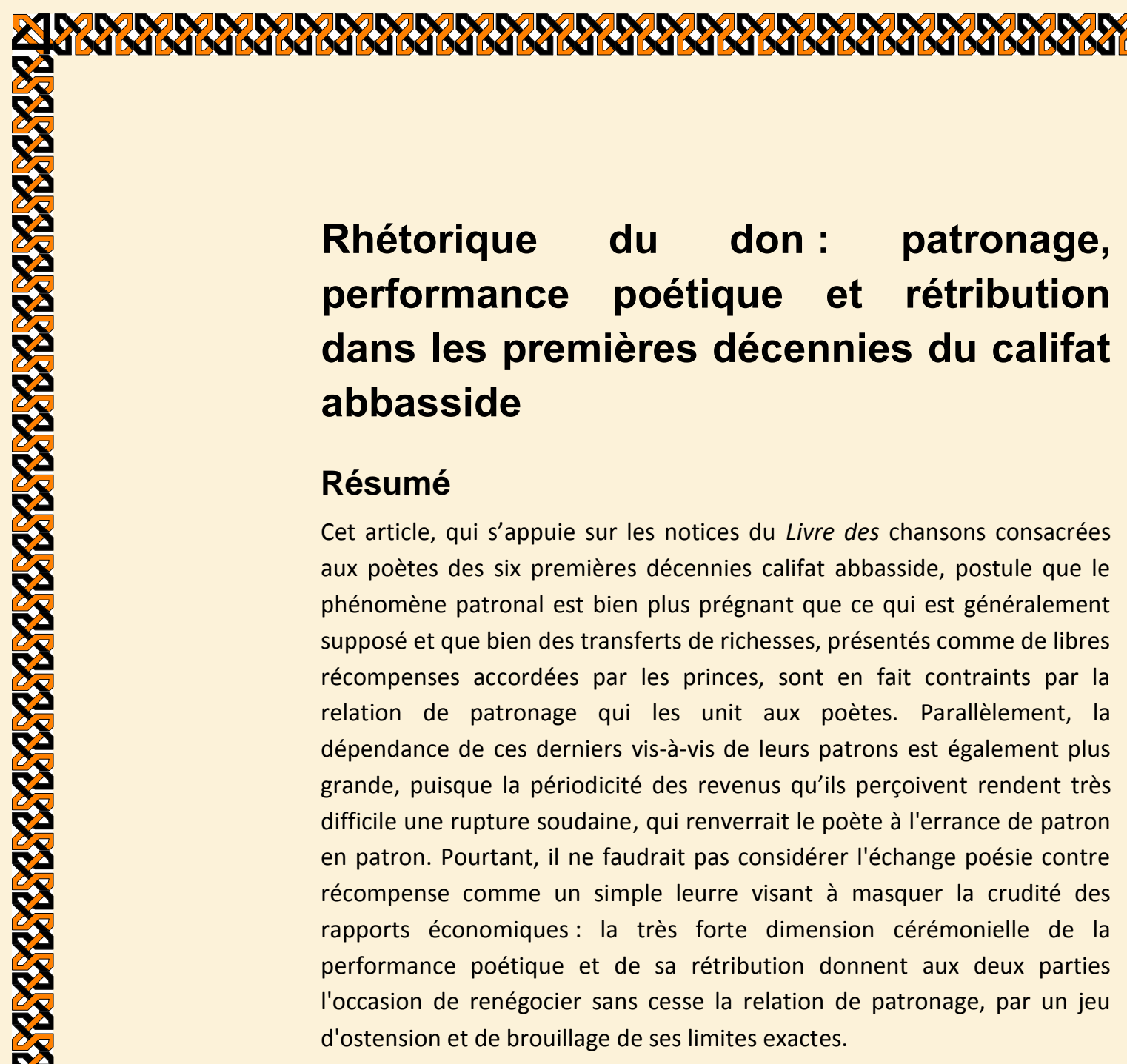

\title{
Mots-clés
}

Poésie arabe (750-810) - patronage - récompense - wifāda - ğirāya inqițā' - euphémisation - poème de mise en demeure (istinğāz)

\begin{abstract}
This article is based on the biographical articles of the Book of Songs dedicated to the poets of the first six decades of the Abbassid caliphate. It postulates that patronage is a much more powerful phenomenon than generally assumed [99]: although wealth transfers are generally presented as free prizes granted by princes, they are in fact constrained by the patronal relationship that binds them to their poets. Similarly, the latters' dependence on their patrons is also stronger than generally supposed, as the frequency of the payments makes a sudden breakdown very unlikely: it would send them back to a life of wandering from court to court. Nevertheless, we should not consider that the exchange of poetry and prizes is just a cover for the harshness of economic relations. There is a strong ceremonial dimension in poetic performance and its payment that allows both parties to renegotiate permanently the patronage relation, through a play of ostentation and blurring of its exact limits.
\end{abstract}




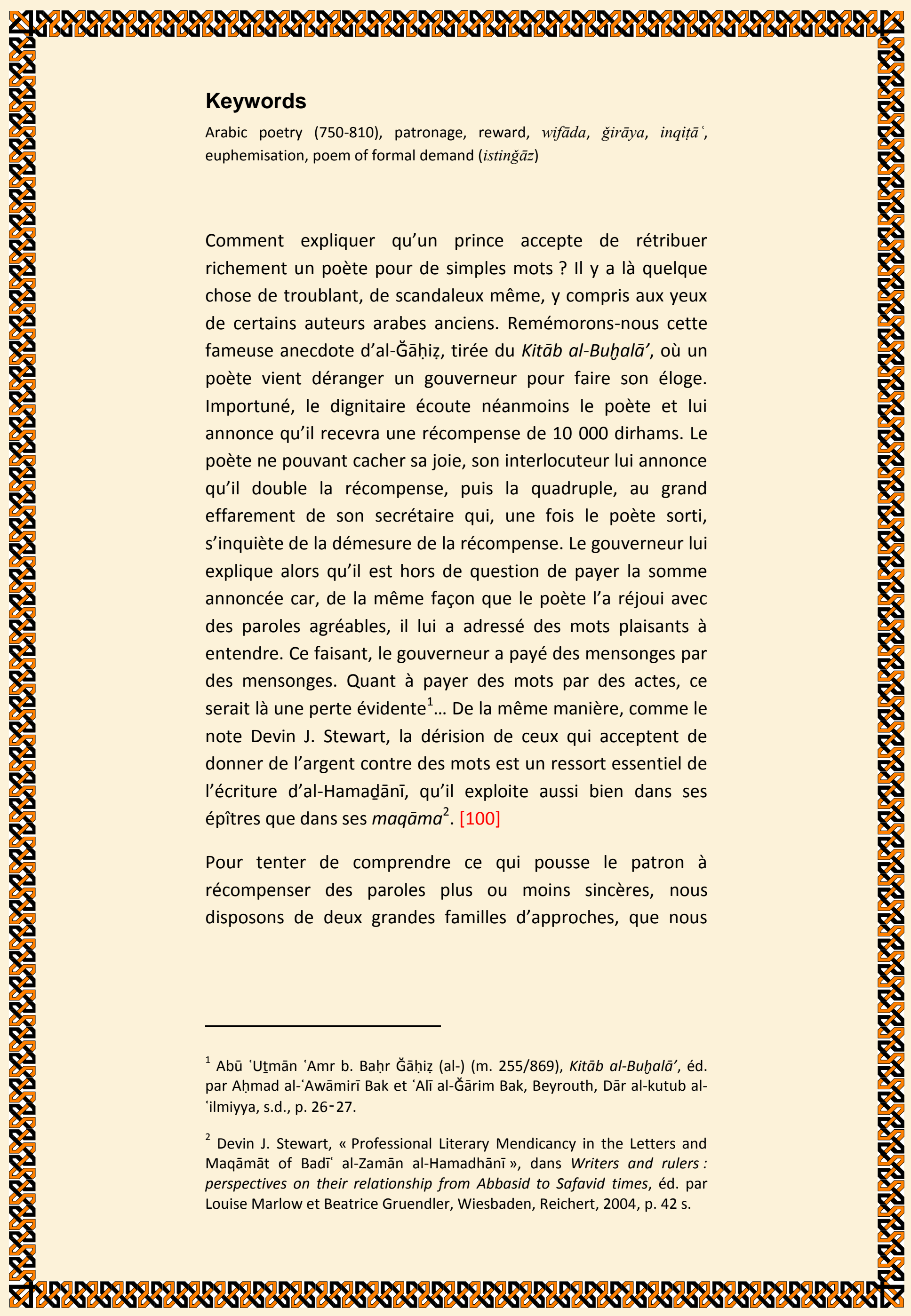




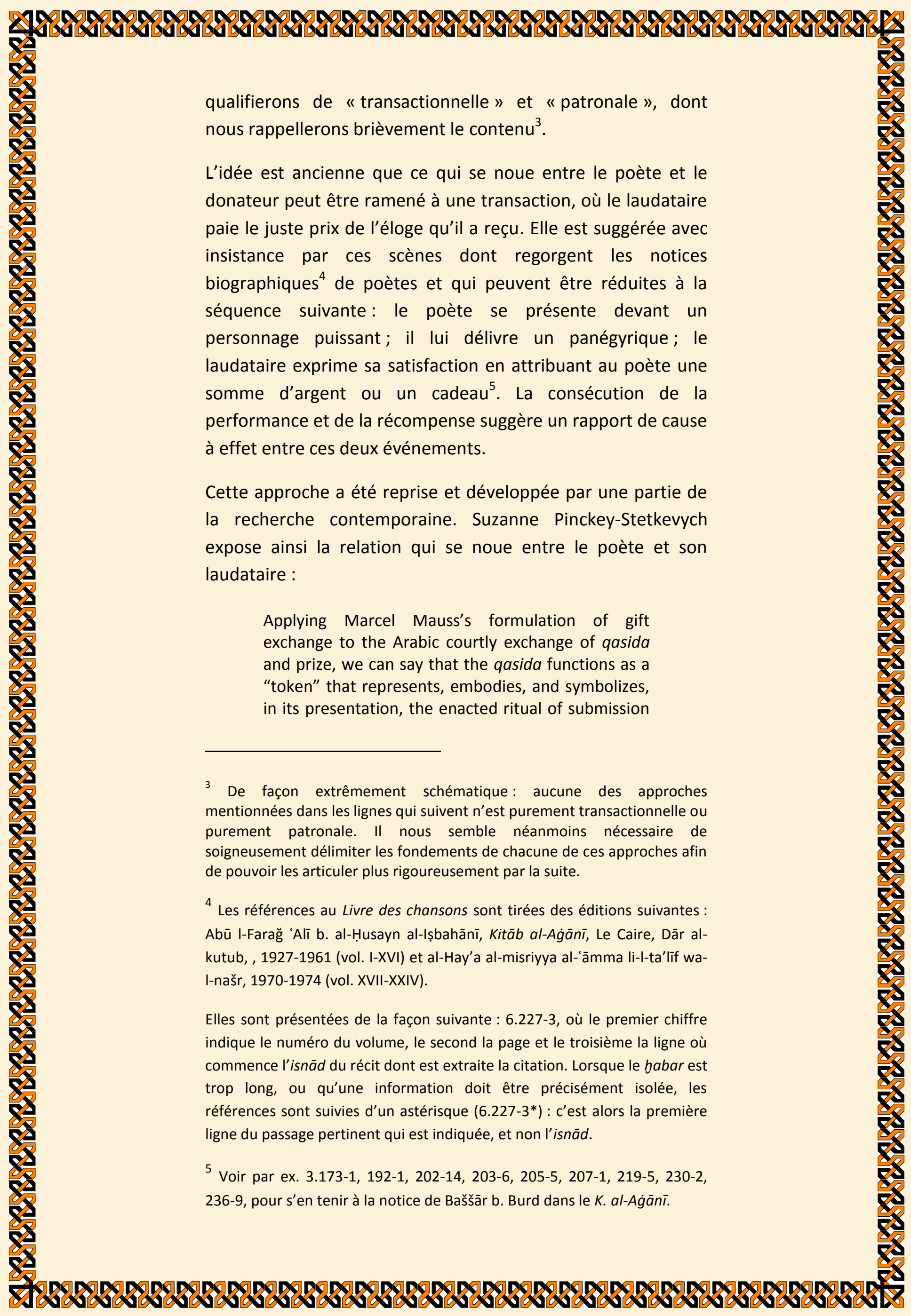




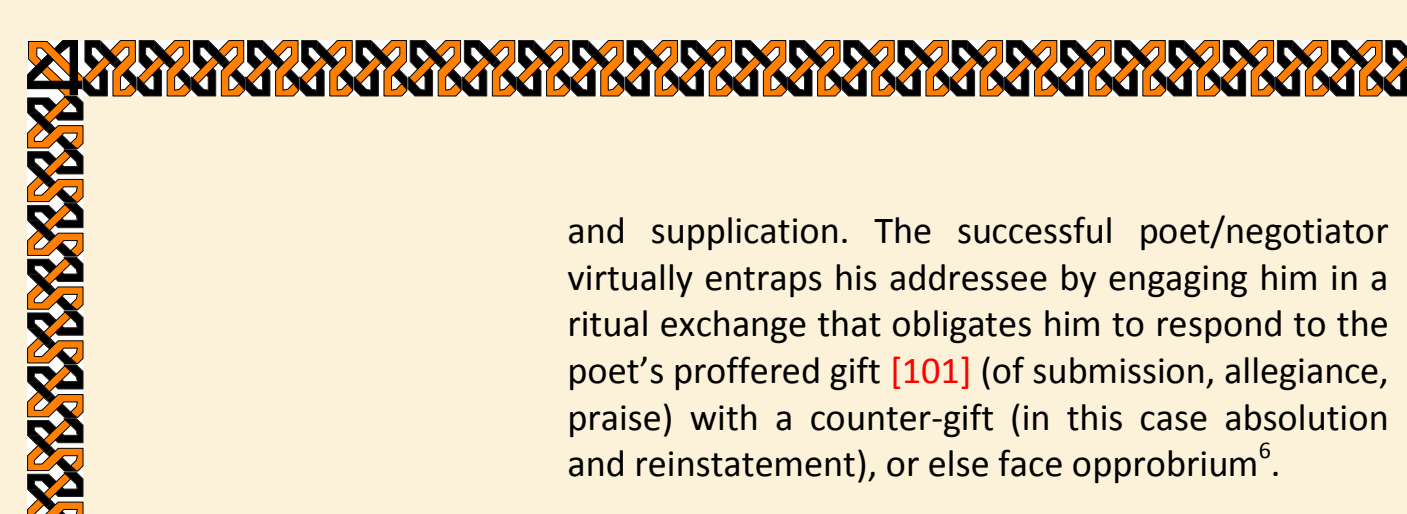

L'idée suggérée par le schéma de consécution dans les ouvrages anciens et explicitée par la théorie du contre-don est que le langage poétique est apte à obliger le laudataire, que le transfert de richesse qui s'ensuit est la rétribution proportionnée de la performance poétique. Cette approche aboutit à envisager que la relation poète/patron est une succession de transactions de ce genre ${ }^{7}$.

Quant à la seconde approche, elle s'est exprimée au cours des années 2000, lorsque divers travaux ont envisagé la relation panégyriste/laudataire non plus dans le cadre de transactions ponctuelles, mais d'une relation plus durable de patronage. Beatrice Gruendler $^{8}$ et, plus récemment, Jocelyn Sharlet ${ }^{9}$, montrent comment la relation durable entre le poète et son patron conditionne la production des œuvres poétiques et peut se lire dans leur structure. Ce saut qualitatif a été permis par l'ouvrage pionnier de Roy Mottahedeh ${ }^{10}$, mais également par l'analyse de corpus plus vastes, là où les ouvrages des années 1980 et 1990 s'appuyaient essentiellement sur l'analyse de qașida isolées.

\footnotetext{
${ }^{6}$ Suzanne Pinckney Stetkevych, The poetics of Islamic legitimacy: myth, gender, and ceremony in the classical arabic ode, Bloomington, Indiana University Press, 2002, p. 18.

7 Dans le même ouvrage, Suzanne Pinckney-Stetkevych, souligne néanmoins que don et contre-don s'inscrivent dans un système où "le suppliant est soutenu par les puissantes institutions et vertus de I'aristocratie guerrière ». Ibid. p. 119.

${ }^{8}$ Beatrice Gruendler, Medieval Arabic praise poetry : Ibn al-Rūmī and the patron's redemption, Londres et New York, RoutledgeCurzon, 2003.

9 Jocelyn Sharlet, Patronage and poetry in the Islamic world : social mobility and status in the medieval Middle East and Central Asia, Londres et New York, I. B. Tauris, 2011.

10 Roy Parviz Mottahedeh, Loyalty and leadership in an early Islamic society, Londres, Tauris Publishers, 2001. L'ouvrage se consacre principalement aux scribes et aux militaires, et ne dit rien des poètes.
} 


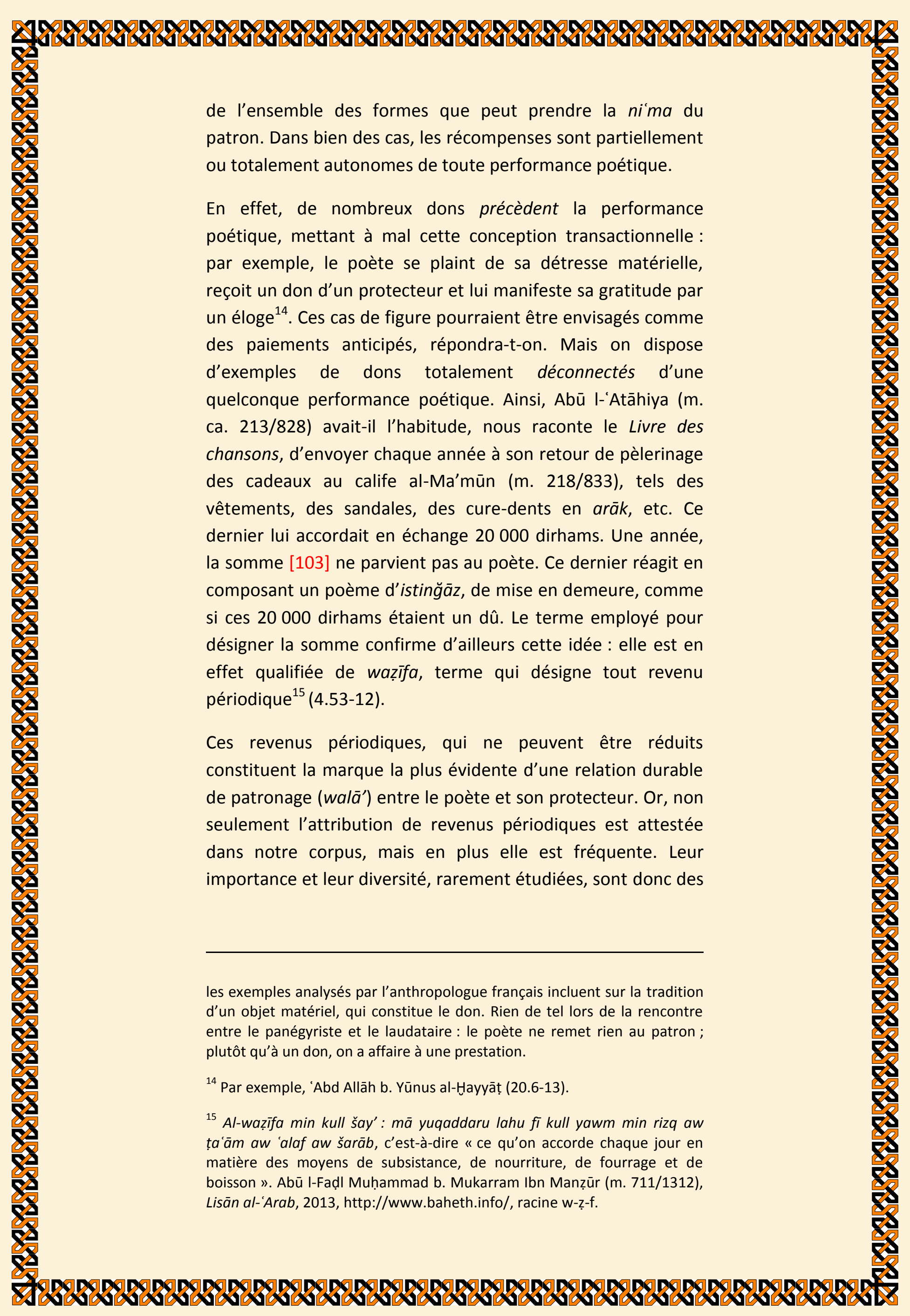




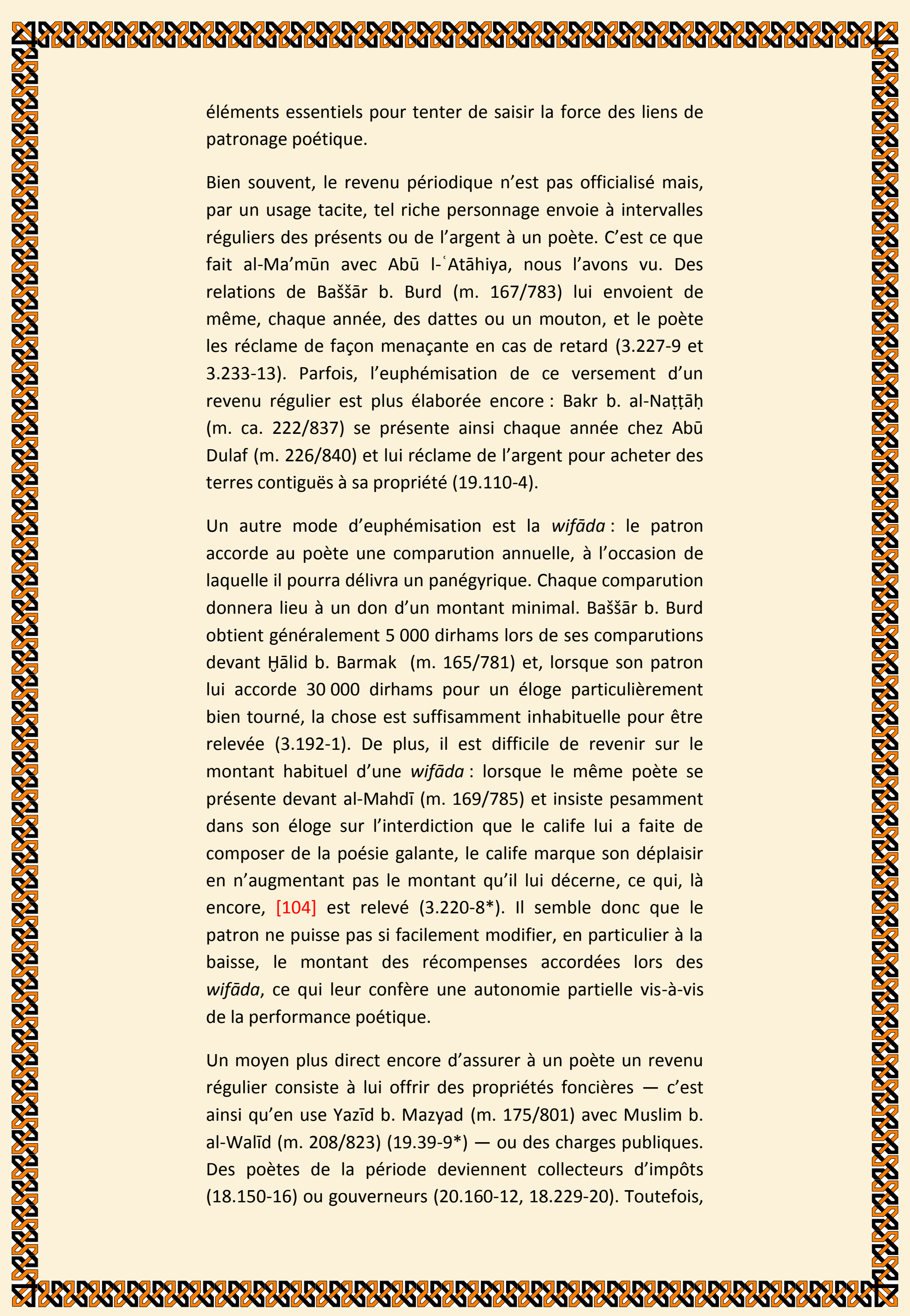




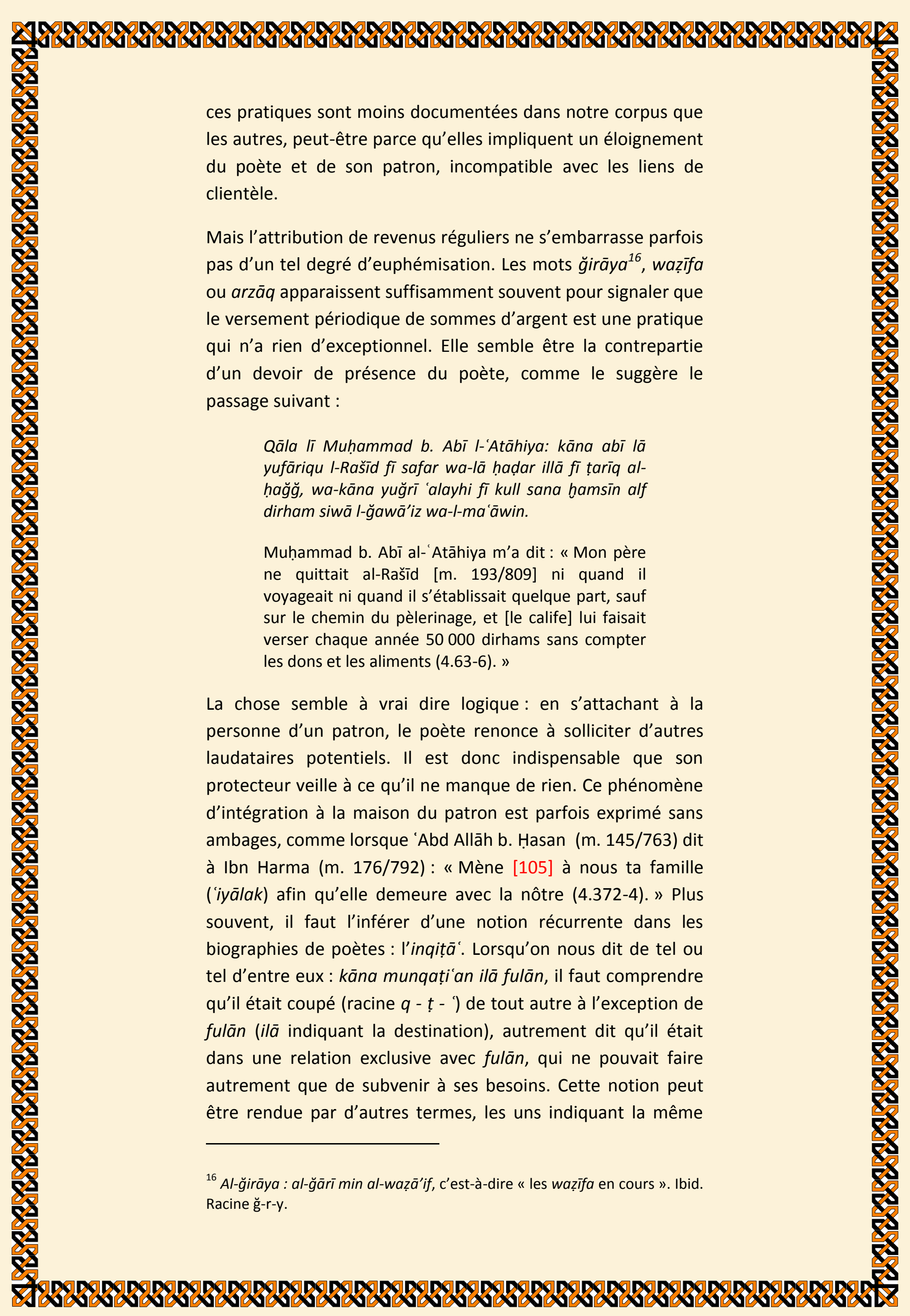




\section{nuance, comme iqtața'ahu ilayhi (le sujet est alors le p
les autres ajoutant une idée de proximité et d'intimité :
(18.318), istașhaba (13.140-13*), qarraba. Marqua
progression de la relation, on lit ainsi à propos d'Abān al-
(m. 200/815) :
Fa-da'a bihi [I-Faḍl b. Yahyā] wa-wașalahu tumma
hușsa bi-I-Faḍl wa-quddima ma'ahu fa-qurriba min qalb Yahyō b. Hālid wa-șāra șāhib al-ğamā'a wa- zimām amrihim.

\begin{abstract}
Al-Faḍl b. Yaḥyā [m. 193/808] le convoqua et le récompensa. II devint par la suite un des intimes d'al-Faḍl et partagea sa bonne fortune. II gagna la sympathie de Yahyaā b. Huâlid [m. 190/805] et devint I'homme de la famille [barmakide] et l'instrument de leur volonté (23.161-1*).
\end{abstract}

Quelle est l'ampleur de ces modes de paiement périodiques? En recensant toutes les preuves ou indices du versement d'un revenu régulier ou d'une relation exclusive, on constate que les deux tiers ${ }^{17}$ environ des poètes de la période mentionnés dans le Livre des chansons bénéficient, à un moment ou à un autre de leur carrière, d'un tel mode de subsistance. De plus, les sommes mentionnées par nos sources, si tant est qu'elles soient fiables, garantissent un niveau de vie fort confortable dans la société abbasside ${ }^{18}$.

Les caractéristiques de ces transferts de richesse périodiques, partiellement déconnectés d'une performance poétique particulière, assurant un mode de vie bien supérieur à la moyenne - doivent nous amener à reconsidérer les rapports entre le poète et le patron. Si ce dernier rémunère de façon [106] continue le poète, la dépendance de ce dernier est bien plus grande que ce qu'une approche transactionnelle laisserait supposer. En effet, si le poète est assimilable à une sorte de commerçant venant proposer sa marchandise à un acheteur potentiel, il a toujours la possibilité de tourner les talons s'il ne trouve pas preneur au prix qui lui convient. En

\footnotetext{
${ }^{17}$ Voir le tableau récapitulatif en annexe.

18 Voir Eliyahu Ashtor, Histoire des prix et des salaires dans l'Orient médiéval, Paris, SEVPEN, 1969.
} 


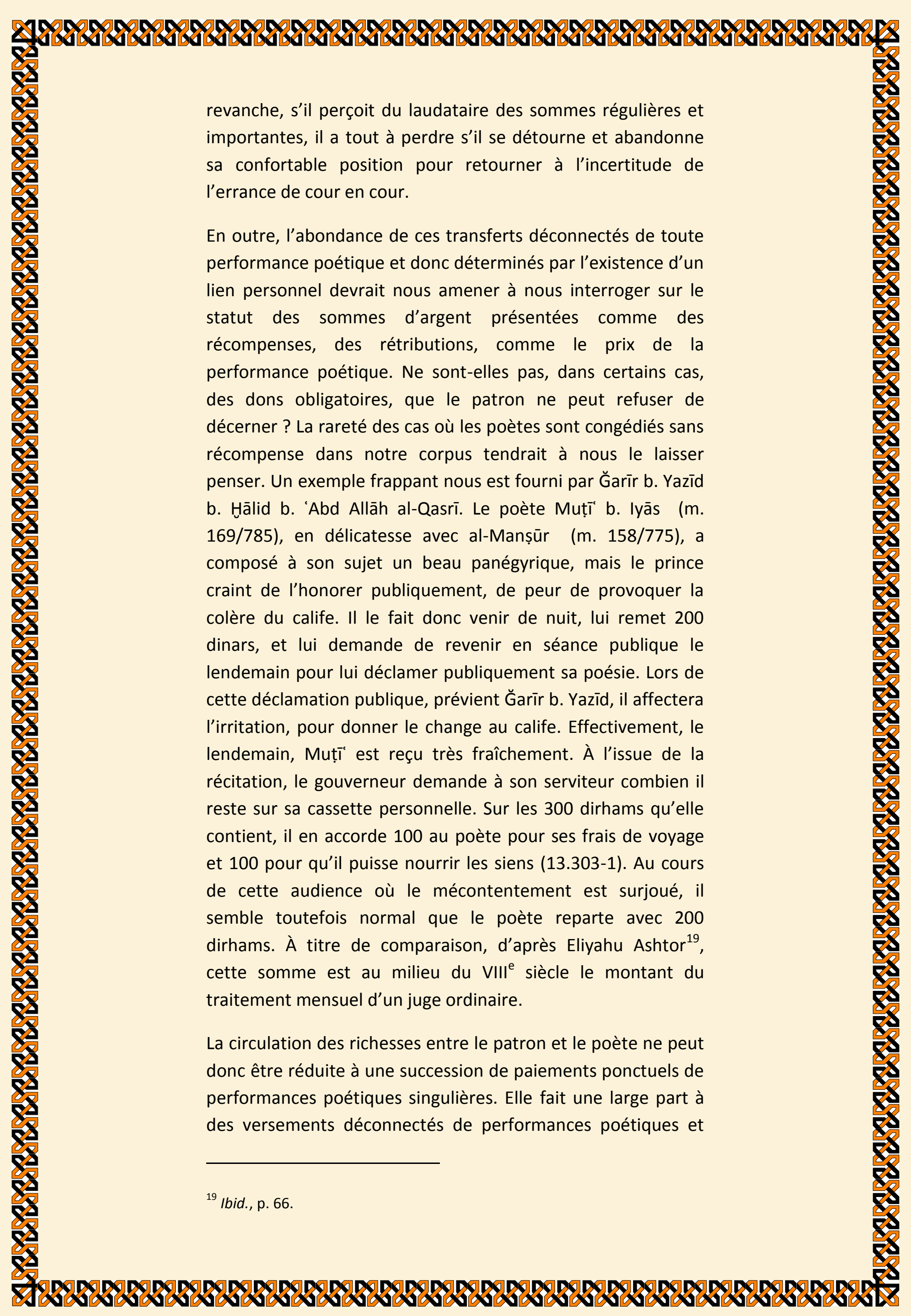




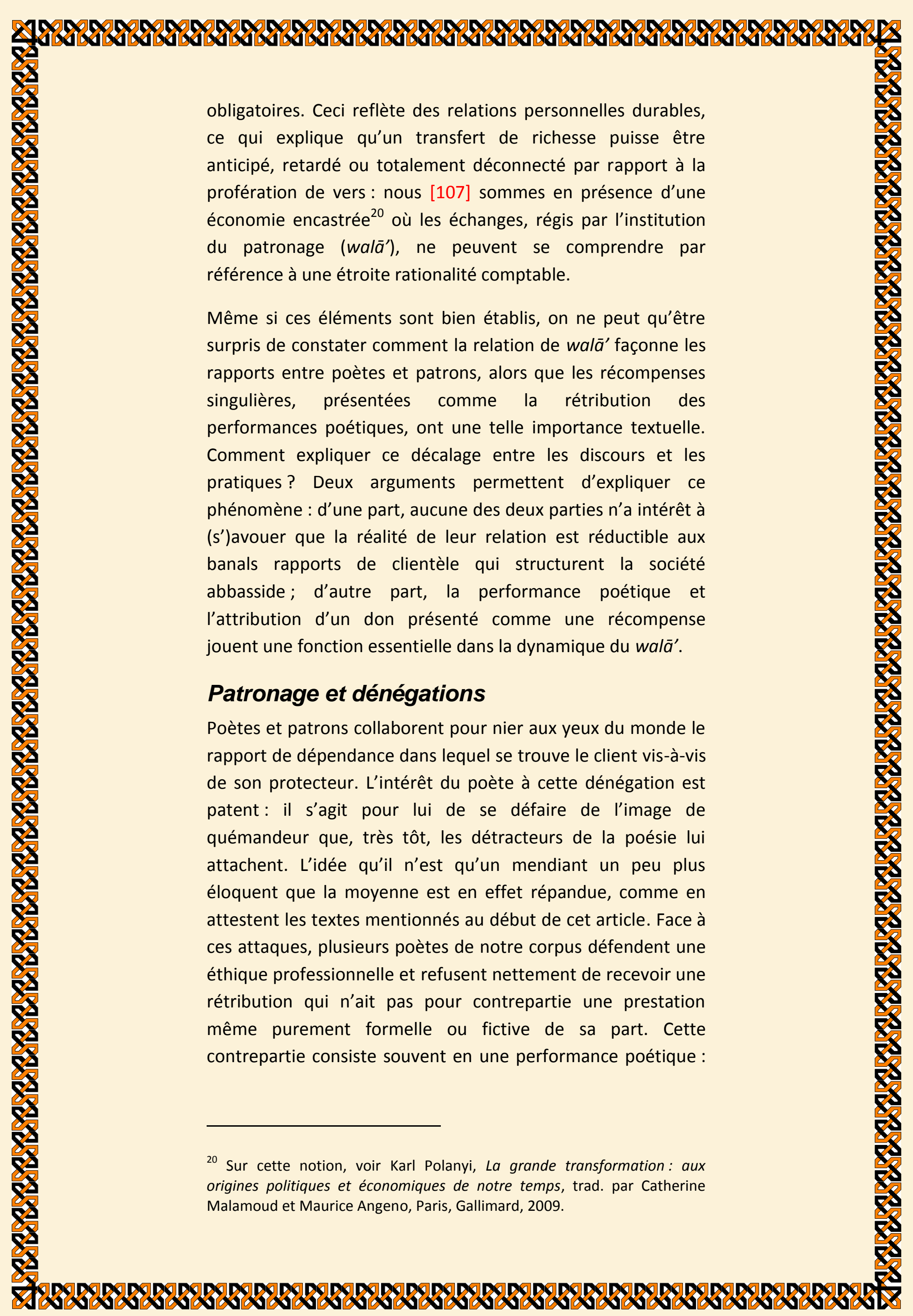




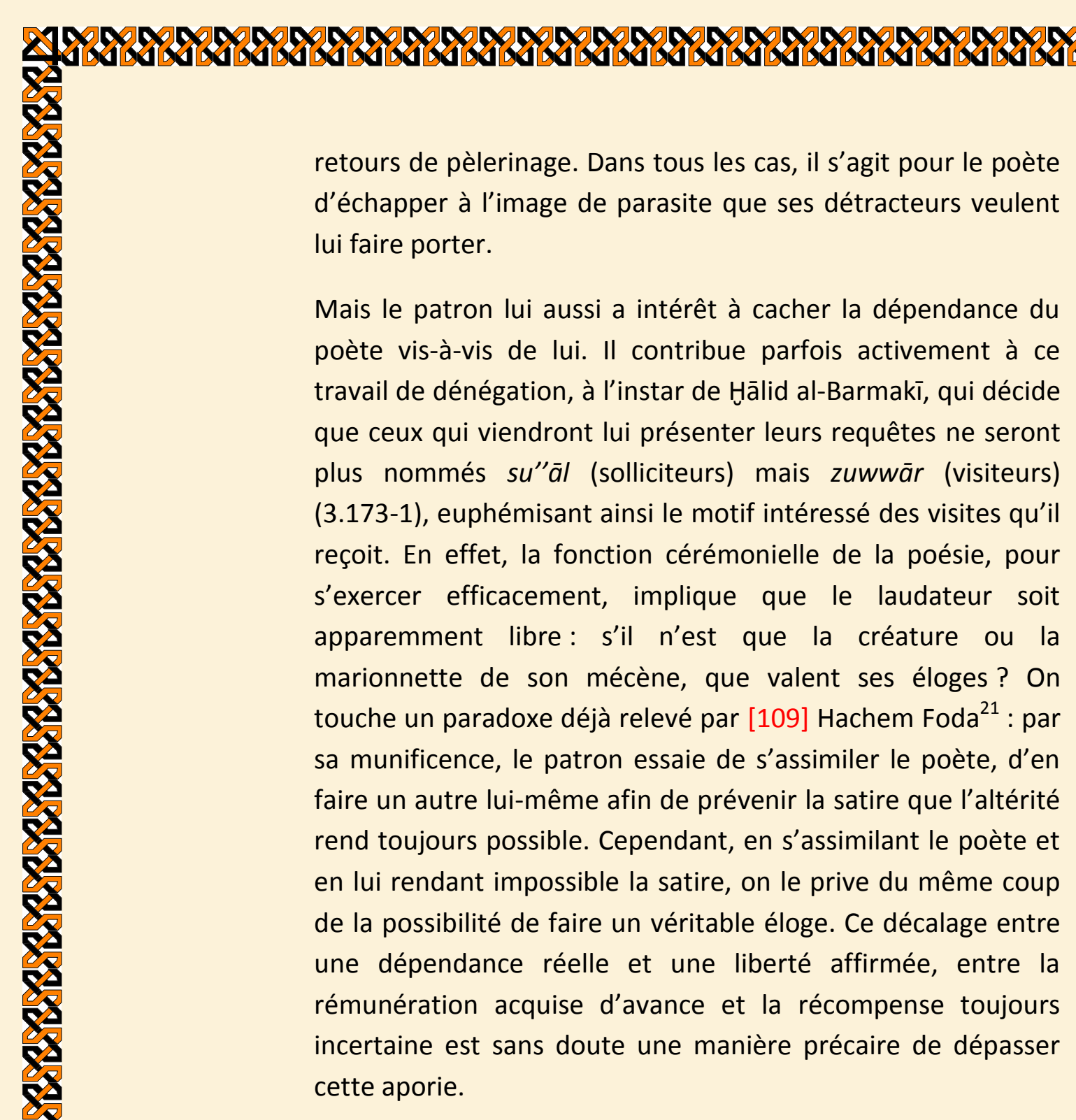

\section{La fonction cérémonielle du don: la négociation du lien de patronage}

La dépendance des poètes est donc bien plus forte que ce que I'on suppose habituellement, puisqu'ils sont attachés, dans le cadre de la relation de wala ${ }^{\prime}$, à un ou plusieurs patrons qui assurent leur subsistance sur la durée. Dans le même temps, les deux parties collaborent fréquemment pour nier tout autre lien que celui instauré par la performance poétique. On pourrait s'en tenir là, satisfait de cette mise au point. L'explication serait cependant un peu courte car elle ne rendrait pas compte de la spécificité du travail poétique. À envisager ce dernier comme une simple superstructure voilant

21 Hachem Foda, "Louanges posthumes", in L'écriture de la nostalgie dans la littérature arabe, éd. par Brigitte Foulon et Kadhim Jihad Hassan, Paris, L'Harmattan, 2013, p. 70. 


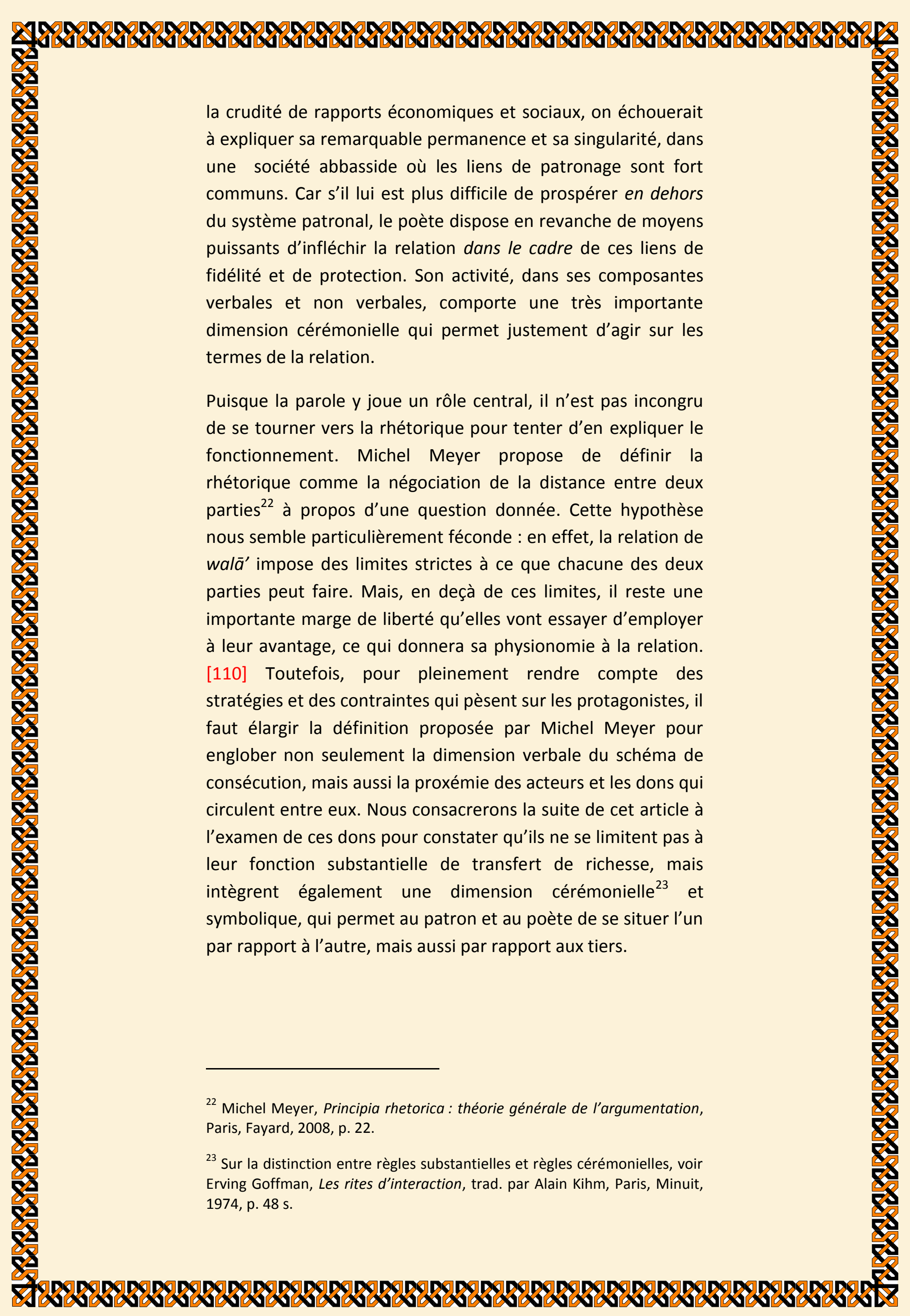




\title{
Ostension du lien
$8 \frac{8}{8}$
S'il transfère des richesses, le don est aussi le signe d'un lien plus ample que celui qui se noue lors d'une transaction ponctuelle. Ceci ressort de nos observations sur le wala', mais également de la terminologie du Livre des chansons. En effet, le don patronal est fréquemment qualifié de șila, c'est-à-dire de lien. Cette homonymie pourrait n'être qu'une coïncidence, mais des explications comme celle d'Ibn Rašīq (m. 456/1064), quelques décennies plus tard, montrent que le rapport entre le don et le lien est présent à l'esprit des contemporains :
}

\begin{abstract}
Al-șila: mā ahaḍa l-rağul min sulțān awwal mā yattașilu bihi, țumma kațura d̦ālika ḥattā qīla li-hibat al-malik « șila ».

Șila : ce que l'on reçoit de l'homme de pouvoir lors du premier contact avec lui. Par la suite, à force d'usage, le mot șila a été employé pour désigner les présents royaux ${ }^{24}$.
\end{abstract}

Mais l'idée que le don est un lien ne s'exprime pas seulement dans les spéculations lexicologiques des savants. Elle se manifeste également par un certain nombre de pratiques, qui nous montrent que la șila continue, après sa délivrance, à rattacher le poète au patron. En témoigne le déplaisir des protecteurs quand ils apprennent le mésusage de leurs dons. Hārūn al-Rašĩd se froisse lorsqu'il apprend qu'al-Sayyid alḤimyarī (m. ap. 171/787) a dépensé [111] en aumônes les 20000 dirhams qu'il lui a accordés (7.277-12). De la même manière, lorsqu'Isḥāq al-Mawșilī (m. 235/850) distribue en rentrant chez lui l'intégralité de la somme que Ṭalha b. Ṭāhir (m. 213/828) lui avait accordée, il se voit fermer la porte de ce dernier pendant trois jours et ne doit son retour en grâce qu'à un vers dans lequel il lui déclare avoir appris la générosité en prenant modèle sur lui (5.335-9). Par ce droit de regard qu'ils s'octroient sur l'usage des dons qu'ils décernent, les patrons montrent que leur argent n'est jamais totalement disponible pour le donataire, car il contient une partie d'eux et du lien qui les unit au poète.

\footnotetext{
${ }^{24}$ Abū 'Alī al-Ḥasan Ibn Rašĩq al-Qayrawānī (m. 456/1064), Al-'Umda fí șinā'at al-ši'r wa-naqdihi, éd. al-Nabawī 'Abd al-Wāḥid Ša'lān, Le Caire, Maktabat al-Hुānğ̄i, 2000, p. 1132.
} 


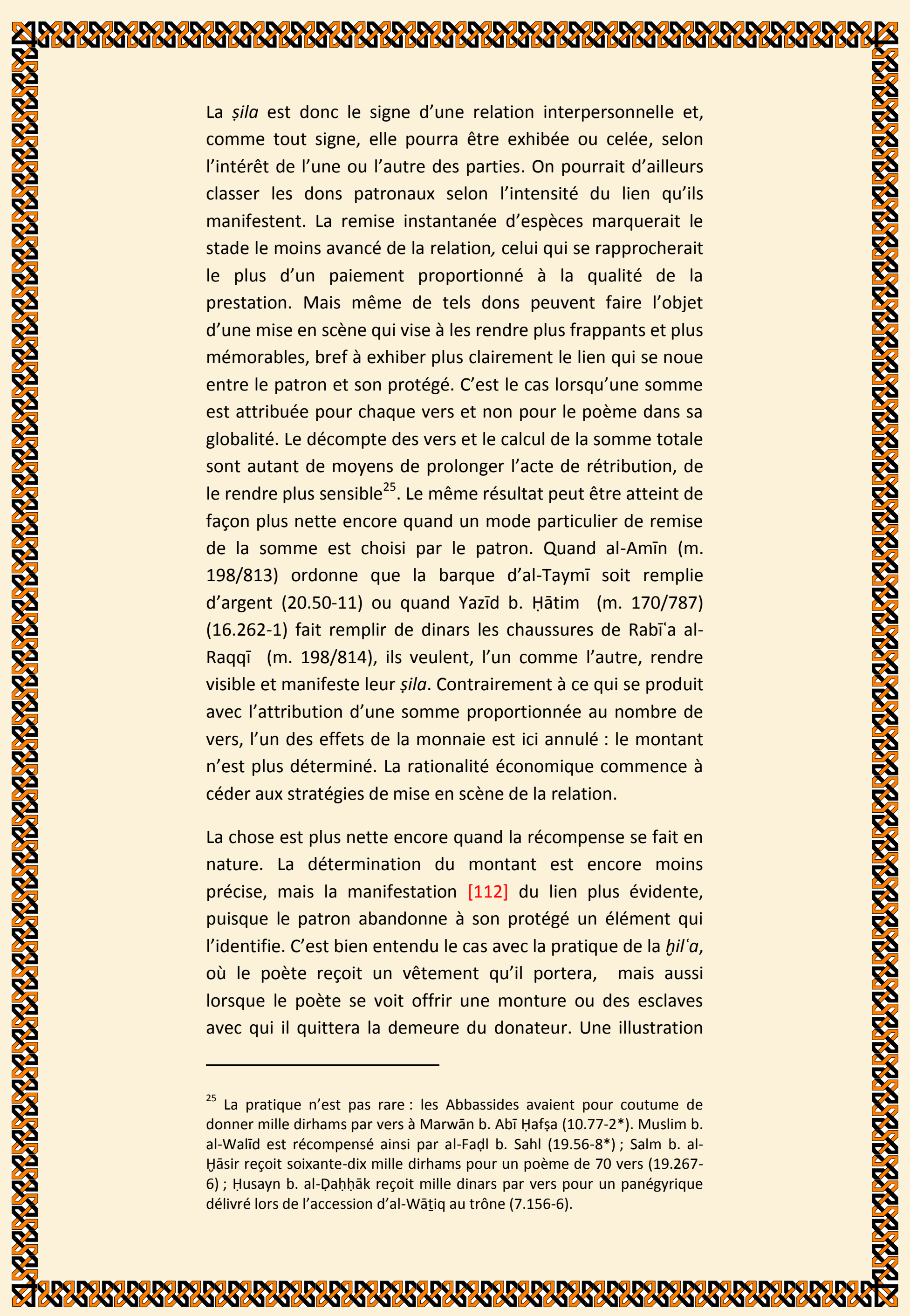




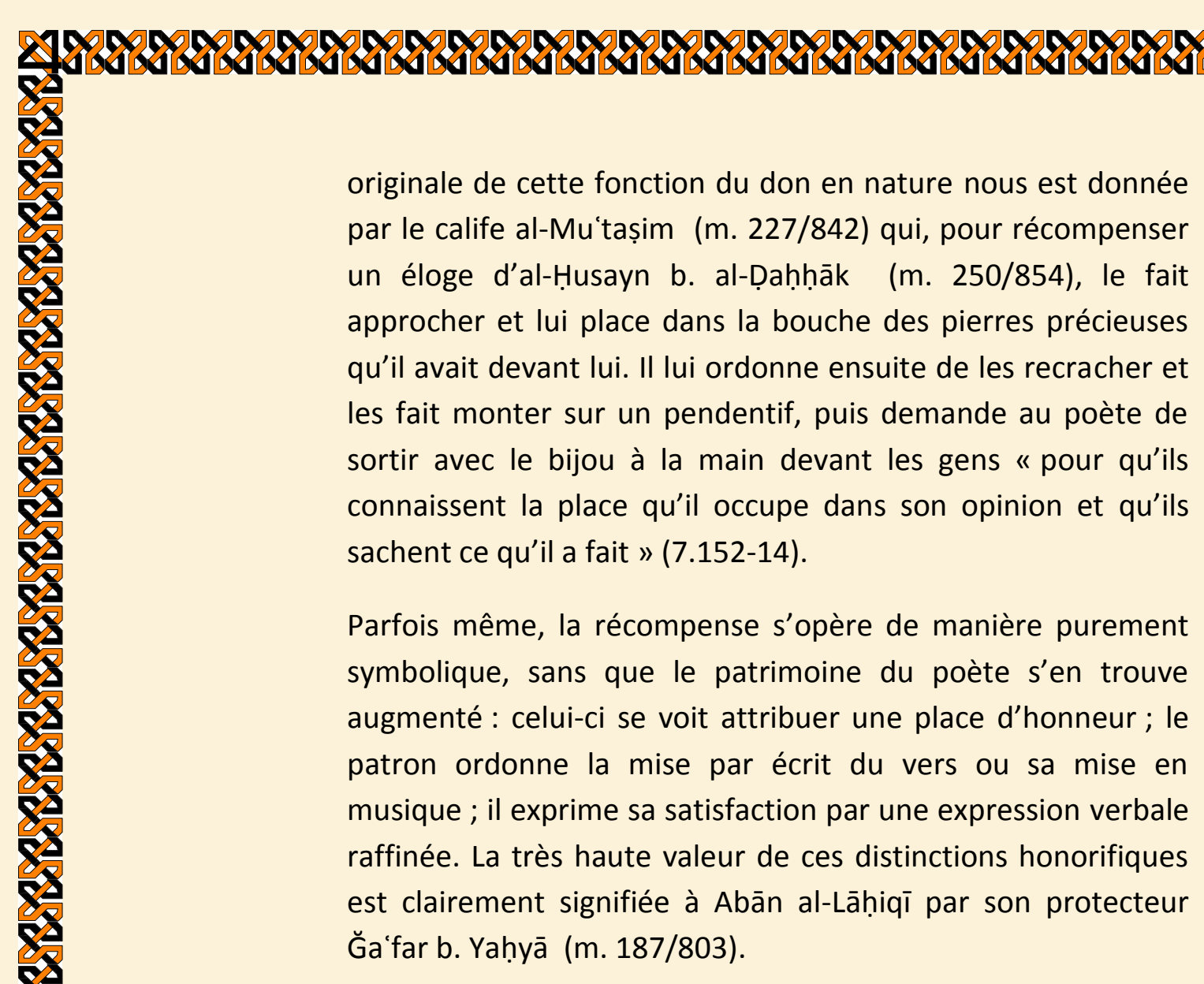

Wa-kāna Abān naqala li-I-Barāmika kitāb Kalīla waDimna fa-ğa'alahu ši'ran, li-yusahhila hifẓahu 'alayhim, wa-huwa ma'rūf, awwaluhu

Hāḍā kitābu adabin wa-miḥna / wa-hwa I-laḍī yud'ā Kalīlah Dimna [sic]

Fīhi ḥtiyālātun wa-fīhi rušdu / wa-hwa kitābun waḍa'athu I-Hindu

Fa-a țā Yahyōa b. Hālid 'ašarat ālāf dīnār, wa-a'țāhu IFaḍl hamsat ālāf dīnār wa-lam yu'ți Ğa'far šay'an wa-qāla: "A-lā yakfi an ahfaẓahu fa-akūna rāwiyatak?»

Abān avait transposé Kalīla et Dimna pour les Barmakides et l'avait mis en vers, afin qu'ils puissent le mémoriser plus facilement. Ce poème est connu et commence par les vers suivants :

Voici un livre plein de savoir et de sagesse: c'est celui que l'on appelle Kalīla et Dimna II contient des ruses et de bons conseils; c'est un livre que les Indiens ont composé.

Yaḥyā b. Haalid lui donna 10000 dinars; al-Faḍl, 5000 ; mais Ğa'far ne lui donna rien : " Ne te suffit-il que je l'apprenne et que je devienne ainsi ton récitant ? » lui demanda-t-il (23.155-10*). [113] 


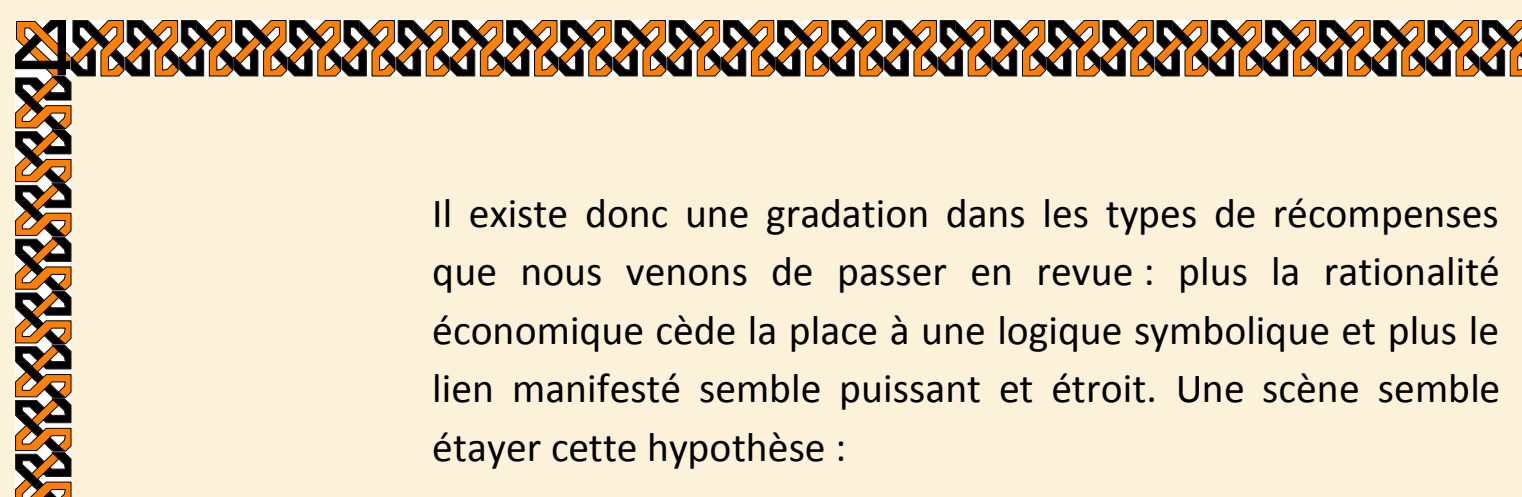

Dahala l-Attābī 'alā 'Abd Allāh b. Tāâir fa-mațala bayna yadayhi wa-anšadahu :

Ḥusnu z̧annī wa-ḥusnu mā 'awwada llā / hu siwāya minka l-gadāta atā bī.

Ayyu šay'in yakūnu aḥsana min ḥus / ni yaqīnin ḥadā ilayka rikābī?

Qāla : fa-amara lahu bi-ğăa'iza, țumma dahala 'alayhi min al-ġad, fa-anšadahu:

Wudduka yakfinīka fī ḥāğatī / wa-ru'yatī kāfiyatun 'an su'āl.

Wa-kayfa aḩšā l-faqra mā 'išta lī / wa-innamā kaffāka lī baytu māl ?

Fa-amara lahu bi-ğă'iza, țumma dahala fí l-yawm alțālit fa-anšadahu :

Bahiğātu I-țiyābi yuhliquhā I-dah / ru wa-țawbu Ițanā’i gadụun ğadīdu.

Fa-ksunī mā yabīdu - aṣlaḥaka Ilā / hu - fa-llāhu yaksūka mā lā yabīdu.

Fa-amara lahu bi-ğă'iza, wa-an'ama 'alayhi bi-hil'a saniyya.

Al-'Attābī [m. 208/823] se rendit auprès de 'Abd Allāh b. Tāhir [m. 230/844]. Lorsqu'il parut devant lui, il lui récita :

C'est la bonne opinion que j'ai de vous et vos bienfaits, auxquels Dieu a habitué d'autres que moi, qui m'amènent aujourd'hui devant vous.

Quoi de meilleur que cette belle certitude qui a guidé vers vous ma monture?

[Le prince] lui fit remettre une récompense. [Al'Attābī] se présenta le lendemain et lui récita :

L'amour de vous comble à lui seul mes désirs, et votre vue rend inutile toute sollicitation.

Comment craindrais-je la pauvreté tant que vous vivrez, puisque vos mains sont pour moi un trésor? [114] 


\section{9.
['Abd Allāh b. Țāhir] lui fit remettre une
récompense. [Le poète] se présenta le troisième jour et récita : \\ Le temps vient à bout des plus beaux vêtements, mais les louanges sont un habit toujours neuf comme au premier jour. \\ Donnez-moi des habits qui passeront - que Dieu vous bénisse - et Dieu vous vêtira de vêtements immortels. \\ II lui fit remettre une récompense et lui offrit un splendide vêtement (13.116-17).}

Lors de ses deux premières venues, le poète se voit offrir une somme d'argent. La troisième fois, son assiduité lui permet d'obtenir un vêtement qui manifeste ostensiblement qu'il existe désormais un lien entre al-'Attābī et 'Abd Allāh b. Tāhir.

Toutefois, cette divergence entre rationalité économique et logique symbolique est parfois intenable. C'est pourquoi alFaḍl b. al-Rabī' (m. 208/823) est amené à réduire une récompense qui avait été publiquement annoncée par le calife al-Amīn (20.50-11).

Tout ceci nous montre comment la șila peut être exhibée à l'initiative du patron, à la double fin d'assurer le poète de sa protection et de montrer aux tiers sa munificence princière en se conformant au modèle du dirigeant idéal. Mais, nous l'avons dit, le schéma de consécution est le lieu d'une négociation et le poète peut avoir intérêt à exhiber lui aussi le lien qui l'unit à son protecteur, contre le gré de celui-ci. II arrive que la somme décernée ne soit pas immédiatement remise au lauréat: celui doit attendre que l'ordre du patron soit exécuté... ou non. Dans cette dernière hypothèse, le poète dispose d'un recours : délivrer au patron un poème d'istinğāz. Par cette en demeure, le poète republie ${ }^{26}$ la promesse : le patron, s'il refuse de s'acquitter de cette promesse publiée et republiée, perd le bénéfice de s'être conformé au modèle du dirigeant idéal et attache à sa personne la flétrissure du

${ }^{26}$ Ou menace de le faire: les poèmes de mise en demeure sont fréquemment adressés sous la forme de billets, qui portent la menace implicite d'une publication si la demande n'est pas satisfaite. La forme du poème d'istinğāz est une des modalités de négociation de la distance. 


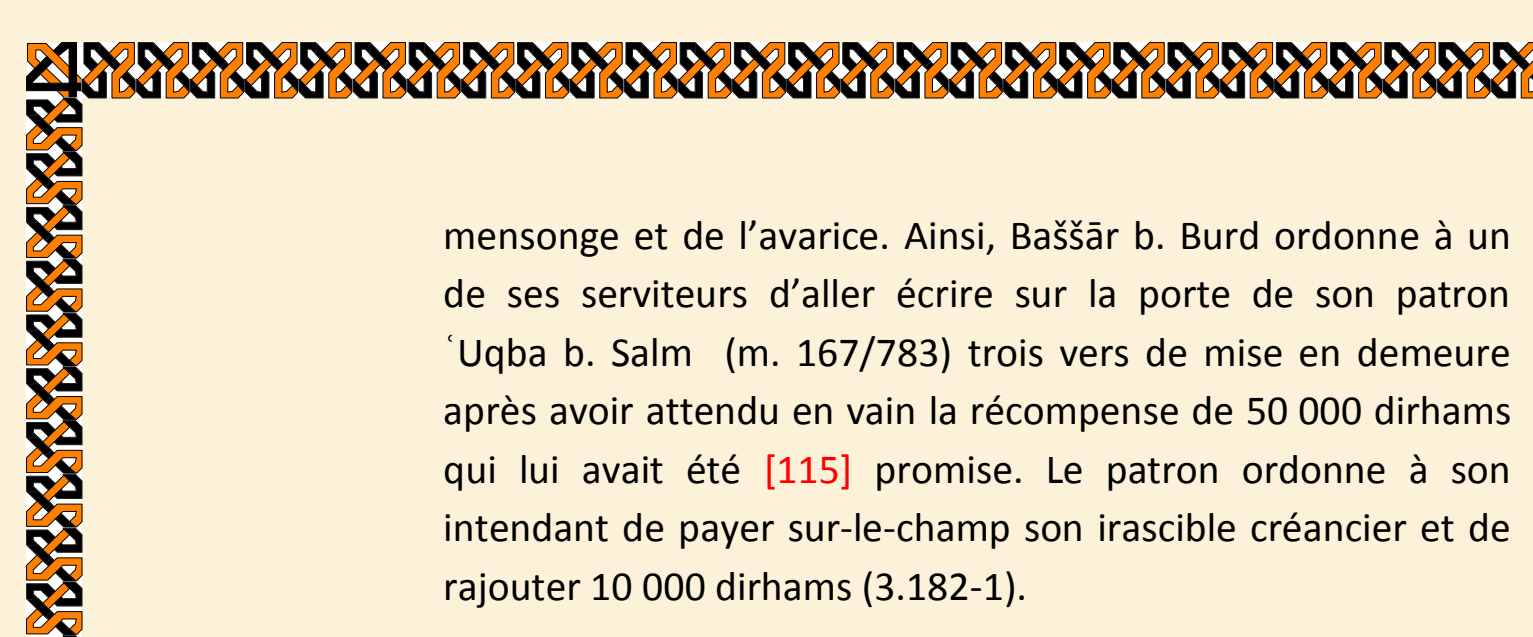

\section{Brouillage du lien}

Dire que l'ostension du lien patronal est donc un enjeu de négociation entre les parties, c'est dire en creux que certains ont parfois intérêt à le maintenir dans une confortable ambiguïté quand d'autres veulent des assurances publiques. Le don entre donc dans des stratégies d'ambiguation et de brouillage qui s'adressent aussi bien au partenaire qu'au tiers.

Les dons, particulièrement quand ils sont fait en espèces, permettent de fixer exactement la valeur du poète aux yeux du patron. Or, en la matière, trop de précision peut être nuisible et froisser les susceptibilités des clients. On ne s'étonnera donc pas de voir les patrons abandonner à l'occasion la fixation du montant au poète concerné. Évidemment, la liberté qui lui est ainsi accordée n'est qu'apparente: le calife al-Manșūr informe en privé Abū Dulāma (m. 161/778 ou 170/786), qui avait fixé, à son invitation, le prix d'un de ses panégyriques à 10000 dirhams, que s'il avait réclamé plus, il aurait été exécuté. Le poète ne peut donc pas réclamer trop de peur d'irriter son protecteur. Mais réclamer trop peu est également risqué : invité à choisir le montant de sa récompense, Marwān b. Abī Ḥaf̦̣a (m. ca. 181/796) réclame 10000 dirhams. "Nous venons de gagner 90000 dirhams à tes dépens » lui lance son protecteur (10.911).

Le poète peut lui aussi tirer parti de l'ambiguïté des relations et de leurs manifestations pécuniaires, en particulier quand il reçoit un don en nature. En effet, la remise d'un objet peut motiver une nouvelle demande: le donataire réclamera l'accessoire du premier présent. Un fameux exemple nous est donné par Abū Dulāma: invité à choisir sa récompense, il réclame un chien pour chasser; l'animal obtenu, le poète réclame une monture pour chasser ; le cheval obtenu, c'est un 


\section{esclave qui est demandé, afin de tenir le chien. Abū Dulāma parvient ainsi à obtenir une esclave pour cuisiner, puis une maison pour loger tout ce monde, puis une propriété foncière pour les nourrir (10.236-13). Sans doute ce récit est-il trop excessif pour être vrai ; toutefois, il est permis de penser que la pratique de négocier l'accessoire d'un don en nature n'a rien d'imaginaire. En témoigne la réaction d'un gouverneur de Kūfa qui, ayant offert un manteau à al-Sayyid al-Ḥimyarī, reçoit une nouvelle demande de sa part, [116] portant cette fois sur un pantalon. Pour couper court à toute nouvelle demande, le gouverneur lui fait adresser une hil'a complète et un cheval de race (7.270-10). \\ Mais, pas plus que l'ostentation, l'ambiguation ne s'adresse qu'au partenaire de la relation de patronage. II peut être souhaitable de ne pas manifester trop nettement aux yeux des tiers l'étendue exacte de la relation. C'est notamment le cas lorsque le calife impose un plafond implicite aux récompenses : voici comment se comporte al-Faḍl b. Yaḥyā après avoir entendu un poème que Muslim b. al-Walĩd lui avait dédié :}

Qāla : fa-țariba I-Faḍl țaraban šadīdan, wa-amara bi-an tu'adda l-abyāt, fa-'uddat fa-kānat țamānīn baytan fa-amara lahu bi-țamānīn alf dirham, waqāla : "lawlā annahā akțar mā wușila bihi l-šu'arā' la-zidtuka, wa-lakinnahu ša'w lā yumkinunī an atağāwazahu - yainī anna l-Rašíd rasamahu liMarwān b. Abī Hafșa - wa-amarahu bi-l-ğulūs ma'ahu wa-l-muqām 'indahu li-munādamatihi, faaqāma 'indahu wa-šariba ma'ahu, wa-kāna 'alā ra's al-Faḍl wașîfa tasqīhi ka'annahā lu'lu'a, fa-lamaha lFaḍll Musliman yanz̧uru ilayhā, fa-qāla : " qad - wa-

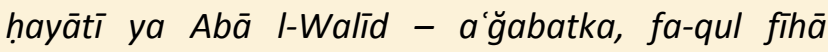
abyātan hattā ahabahā laka. Fa-qāla:

In kunti tasqīna gayra I-rāḥi fa-sqīnī / ka'san aladِḍu bihā min fïki tašfīnī (...)

Fa-qāla lahu: "Hud̆hā - būrika laka fïhā - waamara bi-tawğīhihā ma'a ba'ḍ hadamiha ilayhi.

Al-Faḍl en conçut un plaisir intense. Il ordonna qu'on compte les vers, ce qui fut fait. II y en avait 80 . II attribua [à Muslim] 80000 dirhams et ajouta : « Ceci est le maximum qui ait été accordé aux poètes ; sans quoi, je t'aurais donné davantage. Mais c'est une 


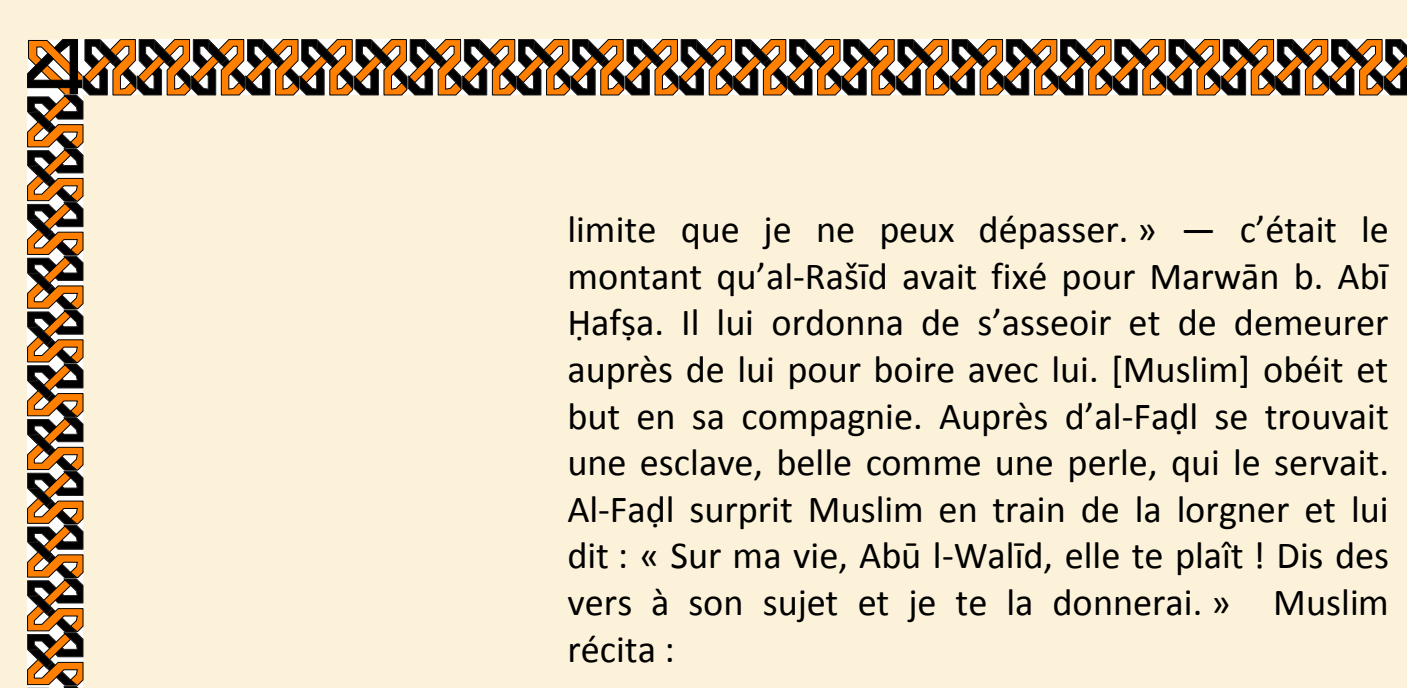

Si tu dois me donner autre chose que du vin, alors
laisse-moi goûter à ta bouche une coupe dont les
délices me guériront (...)

« Prends-la. Félicitations ! » lui dit [al-Faḍl]. II la lui fit envoyer, avec quelques-uns de ses serviteurs (19.58-17). [117]

Enfin, la faveur que reçoit le poète requiert parfois la plus grande discrétion. C'est le cas lorsque le protecteur accorde un passe-droit: celui-ci n'a pas pour fonction d'être exhibé ; il doit au contraire rester caché car il accorde une exception à des règles qui fondent l'autorité de celui qui l'accorde. Lorsque Ibn Harma refuse les dix mille dirhams qu'al-Manșūr lui accorde à l'issue de la récitation d'un panégyrique et réclame à la place la permission de boire du vin, al-Manșūr s'y refuse, car il s'agit d'une prescription divine; le poète insiste néanmoins. Le calife écrit donc au gouverneur de Médine pour lui ordonner de faire donner 80 coups de fouet à lbn Harma s'il est pris en état d'ivresse, et 100 à son dénonciateur (4.375-3). Le poète peut désormais boire sans risque d'être dénoncé, et le commandeur des croyants ne l'a pas formellement dispensé d'obéir à la loi divine.

Les observations qui précèdent invitent donc à une approche quelque peu dédramatisée des rapports entre poètes et laudataires, du moins lorsqu'ils sont engagés dans une relation de patronage: ni l'un ni l'autre ne jouent leur avenir sur un coup de dé. Les revenus des poètes sont, pour une part non négligeable, déconnectés de leurs performances et ne peuvent être remis en cause d'un claquement de doigts. Le patron, quant à lui, sait que la rupture du lien de patronage est fort coûteuse pour le poète, qui ne se retournera pas contre lui à la première contrariété. Les deux parties sont donc incitées à négocier dans le cadre de la relation, qui leur apporte sécurité 


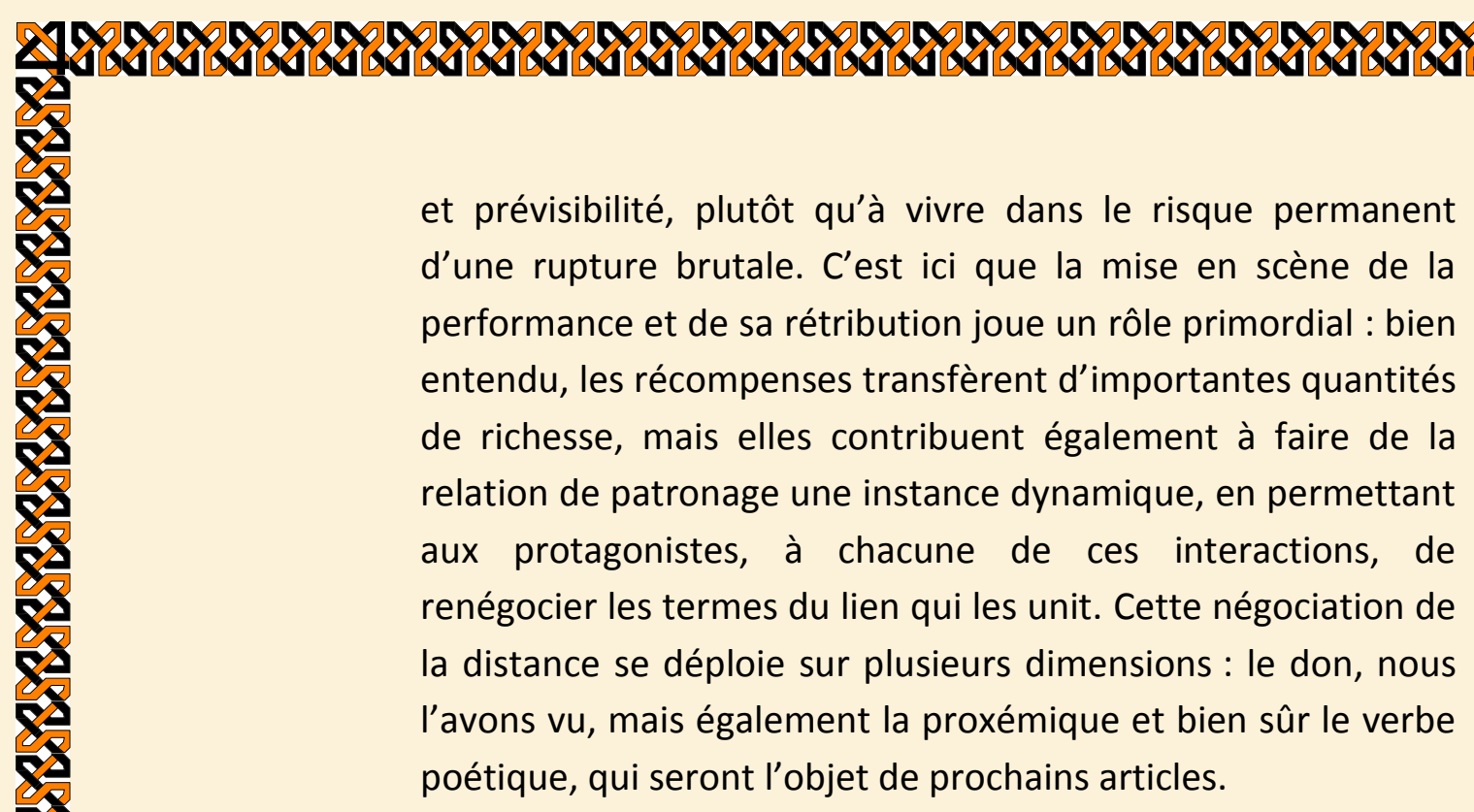

\section{Annexe : tableau des modes de subsistance des poètes}

Ce tableau, pour chacun des 66 poètes dont la notice a été examinée, recherche les indices textuels d'existence d'un lien de $w a l \bar{a}^{\prime}$, en les répartissant en trois catégories :

— Revenu périodique accordé par le patron ;

- Relation exclusive avec un patron (inqițā', iștịhāb, ișținā $\bar{a}^{[118]}$

- Indices divers qui, à la lumière des observations cidessus, suggèrent qu'il existe entre le poète et son protecteur des rapports de solidarité impliquant des transferts de richesse déconnectés de performances poétiques singulières : obligation de présence lors des voyages; attribution de charges publiques ou privées, munādama, secours en cas de détresse.

Le nombre entre parenthèses indique la page où se trouve cet indice textuel.

Ces trois types d'indices se caractérisent de notre point de vue par une force probatoire décroissante. Aussi, pour chaque poète a été recherchée une unique preuve de la plus grande force probatoire: ainsi, une seule des trois colonnes est remplie pour chaque poète. 


\section{Ainsi, pour 14 poètes, un revenu permanent est mentionné. Pour 21 d'entre eux, une relation exclusive. Pour 10 d'entre eux, d'autres indices laissent supposer une relation de patronage durable. Au total, plus des deux tiers des poètes semblent se trouver dans une relation de wala' à un moment ou à un autre de leur carrière. Même si l'on excepte la dernière catégorie d'indices, extrêmement spéculative, on parvient tout de même à un total supérieur à la moitié. \\ Il convient d'avoir à l'esprit qu'il s'agit du recensement d'indices textuels, tirés d'un ouvrage qui n'a pas pour vocation première d'expliciter les conditions économiques d'exercice de l'activité poétique. De plus, cet ouvrage ne traite que de poètes suffisamment fameux pour voir leurs vers mis en musique. Nous ne savons rien de la situation des poètes plus obscurs. Enfin, l'impression de précision qui s'attache aux pourcentages ne doit donc pas faire illusion : nous sommes en présence d'ordres de grandeur très grossiers, d'autant que l'échantillon reste relativement modeste.}

\begin{tabular}{|c|c|c|c|c|}
\hline & Date de mort & $\begin{array}{c}\text { Revenu } \\
\text { permanent } \\
\text { assuré par un } \\
\text { protecteur }\end{array}$ & Inqițā' & $\begin{array}{l}\text { Autres indices d'un lien } \\
\text { de wala } \bar{a}^{\prime}\end{array}$ \\
\hline $\begin{array}{l}\text { Abān b. 'Abd al- } \\
\text { Ḥamīd al-Lāḥiqīi }\end{array}$ & $200 / 815$ & & 23.161-1* & \\
\hline $\begin{array}{l}\text { 'Abd Allāh b. al- } \\
\text { Hayyāț }\end{array}$ & $\begin{array}{l}\text { vivant sous al- } \\
\text { Mahdī }\end{array}$ & $20.9-3$ & & \\
\hline $\begin{array}{l}\text { [119] 'Abd Allāh } \\
\text { b. Ayyūb al-Taymīi }\end{array}$ & $\begin{array}{c}\text { En activité sous } \\
\text { al-Rašīd }\end{array}$ & & $20.44-6^{*}$ & \\
\hline $\begin{array}{l}\text { 'Abd Allāh b. } \\
\text { 'Umar al-'Ablī }\end{array}$ & Ap. $145 / 762$ & & $11.297-6^{*}$ & \\
\hline Abū I-'Atāhiya & ca $213 / 828$ & $4.63-6$ & & \\
\hline Abū 'Ațā' al-Sindī & Av. $158 / 775$ & & & \\
\hline Abū Dulāma & $\begin{array}{l}161 / 778 \text { ou } \\
170 / 786\end{array}$ & & $10.235-5$ & \\
\hline
\end{tabular}




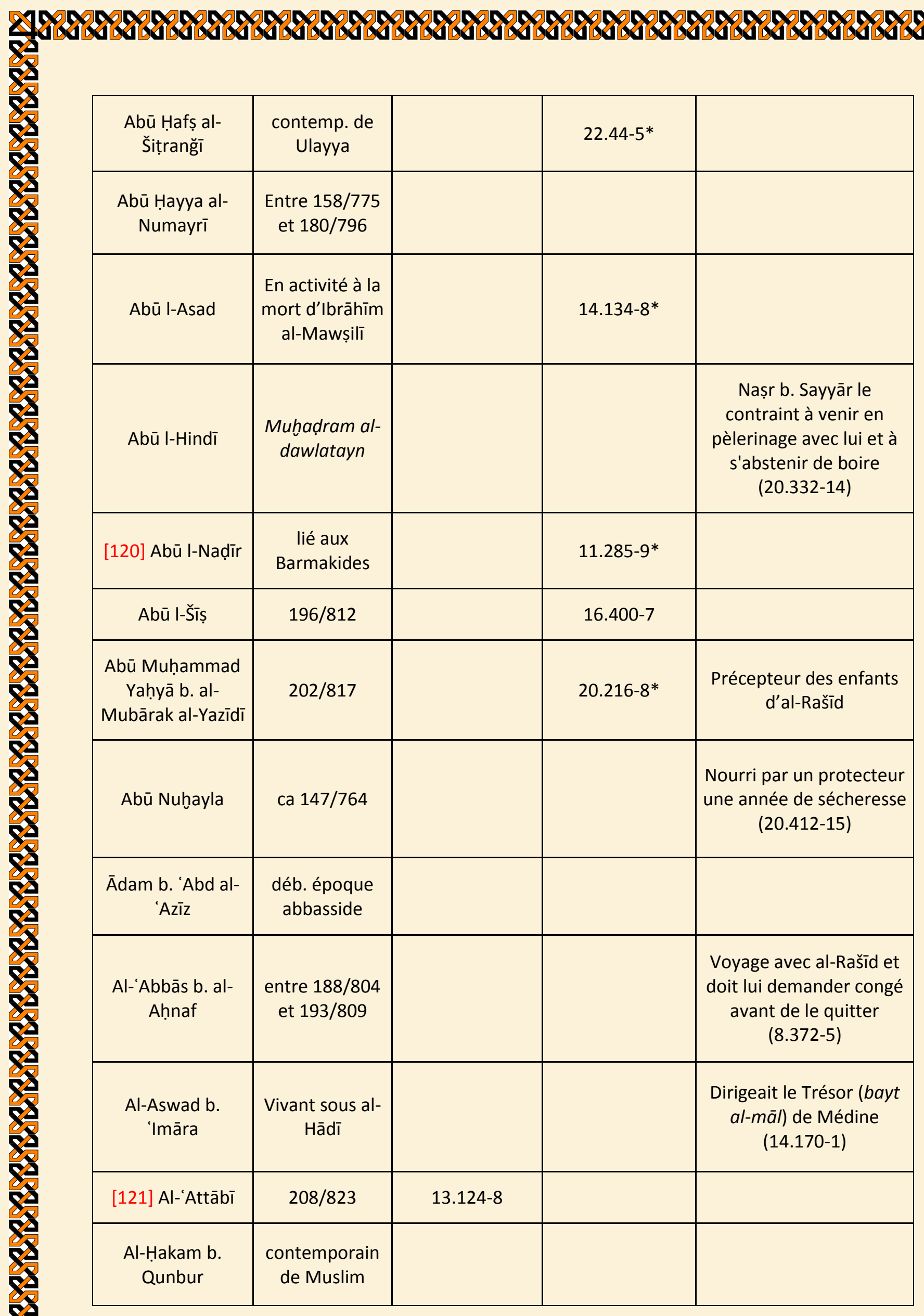




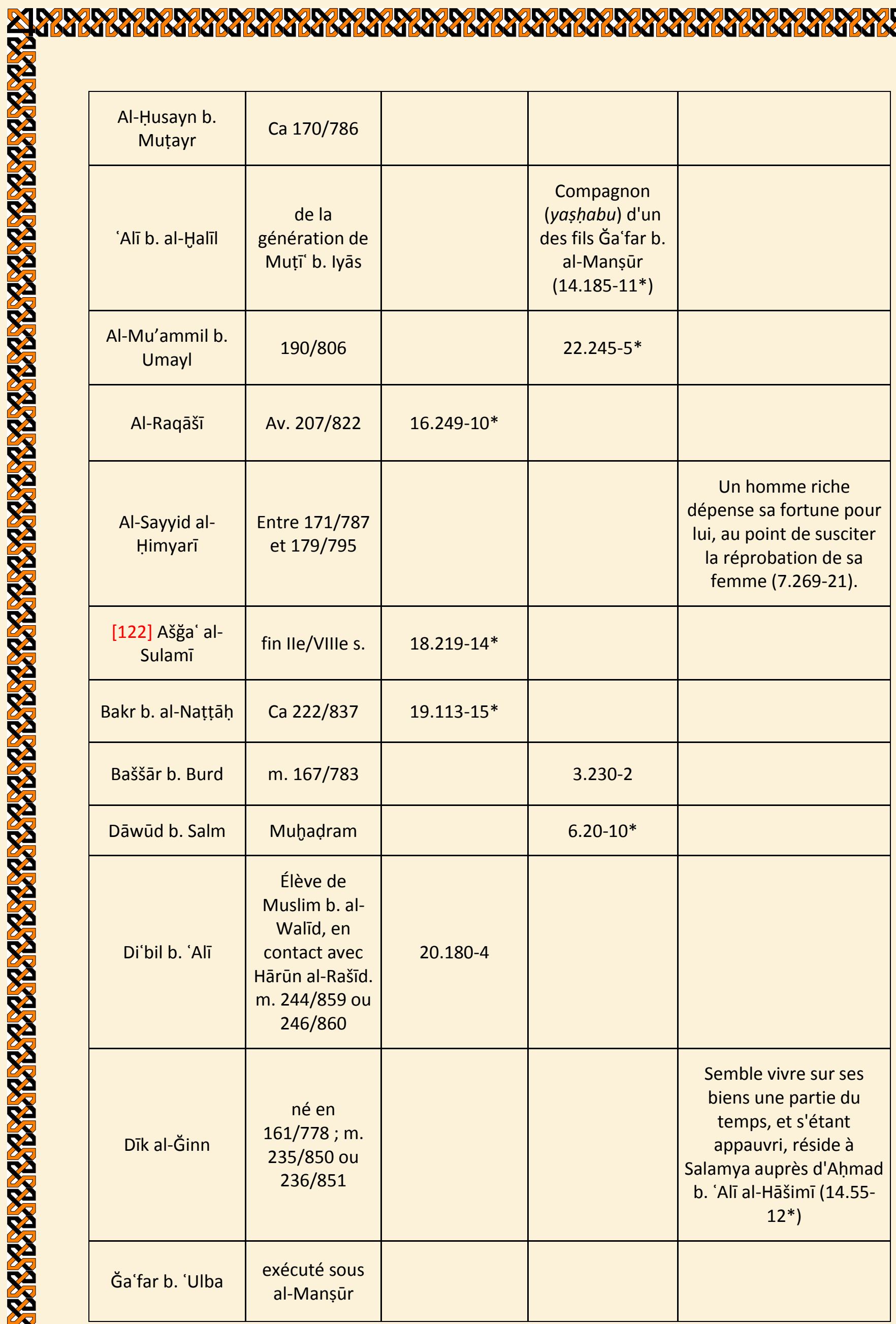




\begin{tabular}{|c|c|c|c|c|}
\hline $\begin{array}{l}\text { [123] Hammād } \\
\text { 'Ağrad }\end{array}$ & $\begin{array}{c}\text { m. entre } \\
155 / 772 \text { et } \\
168 / 784\end{array}$ & & & $\begin{array}{l}\text { Nadīm d'al-Walīd b. } \\
\text { Yazīd (14.335-9) et Nāfi' } \\
\text { b. 'Uqba (14.323) }\end{array}$ \\
\hline $\begin{array}{l}\text { Ḥusayn b. al- } \\
\text { Dahhhāāk }\end{array}$ & $\begin{array}{l}\text { né } 162 / 779 \text {; } \\
\text { m. } 250 / 854\end{array}$ & $7.205-16$ & & \\
\hline Ibn Abī ‘Uyayna & $\begin{array}{l}\text { Ibn Abī } \\
\text { 'Uyayna }\end{array}$ & 20.107-10 & & \\
\hline Ibn al-Dumayna & $\begin{array}{c}\text { 143/760 ou } \\
\text { sous Hārūn al- } \\
\text { Rašīd }\end{array}$ & & & \\
\hline Ibn Mayyāda & $\begin{array}{c}136 / 754 \text { ou } \\
149 / 766\end{array}$ & $2.309-11$ & & \\
\hline Ibn Munādir & m. 198/814 & & & \\
\hline Ibrāhīm b. Harma & $176 / 792$ & $4.377-6^{*}$ & & \\
\hline Ibrāhīm b. Sayāba & $198 / 814$ & & & \\
\hline 'T̄sā b. Mūsā & & & & \\
\hline $\begin{array}{l}\text { [124] Isḥāq b. } \\
\text { Ibrāhīm al- } \\
\text { Mawșilī }\end{array}$ & m. $235 / 850$ & $5.258-5$ & & \\
\hline Ismāīl b. 'Ammār & $\begin{array}{c}\text { Muhad̦ram al- } \\
\text { dawlatayn }\end{array}$ & $11.369-16^{*}$ & & \\
\hline Manșūr al-Namarī & av. 193/809 & & $\begin{array}{c}\text { Istișhāa b (13.140- } \\
\text { 13) }\end{array}$ & \\
\hline $\begin{array}{l}\text { Marwān b. Abī } \\
\text { Hafșa }\end{array}$ & $\begin{array}{l}181 / 796 \text { ou } \\
182 / 797\end{array}$ & & & \\
\hline $\begin{array}{c}\text { Muḥammad b. } \\
\text { Du'ayb al-'Umānī }\end{array}$ & $\begin{array}{l}\text { Mort sous } \\
\text { Hārūn al-Rašĩd } \\
\begin{array}{c}(170 / 786- \\
193 / 809)\end{array}\end{array}$ & & $18.318-11$ & \\
\hline $\begin{array}{l}\text { Muḥammad b. } \\
\text { Kunāsa }\end{array}$ & $207 / 823$ & & & \\
\hline $\begin{array}{c}\text { Muhammad b. } \\
\text { Umayya }\end{array}$ & $\begin{array}{l}\text { En activité sous } \\
\text { al-Rašĩd. }\end{array}$ & & $12.145-6 *$ & \\
\hline
\end{tabular}




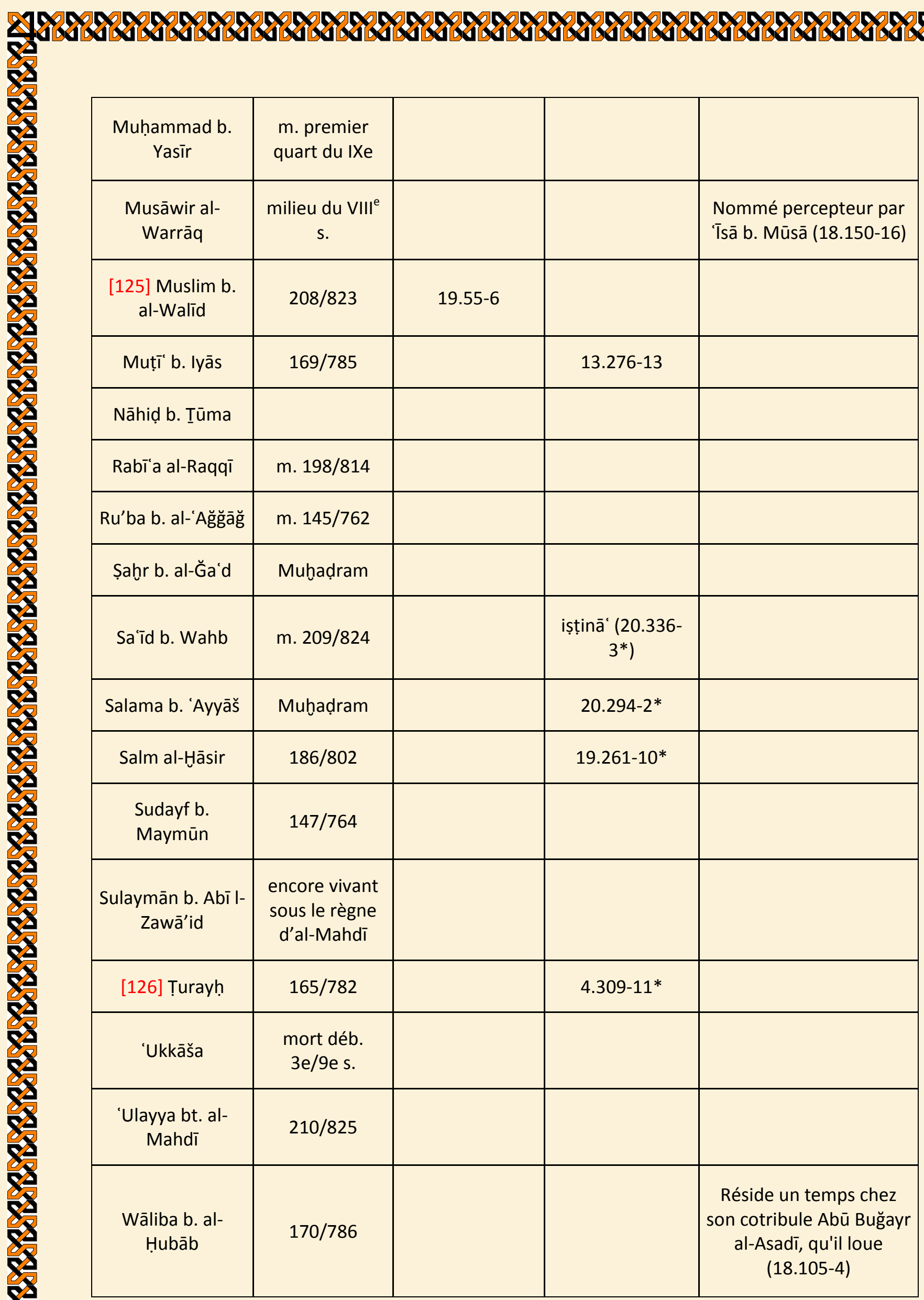




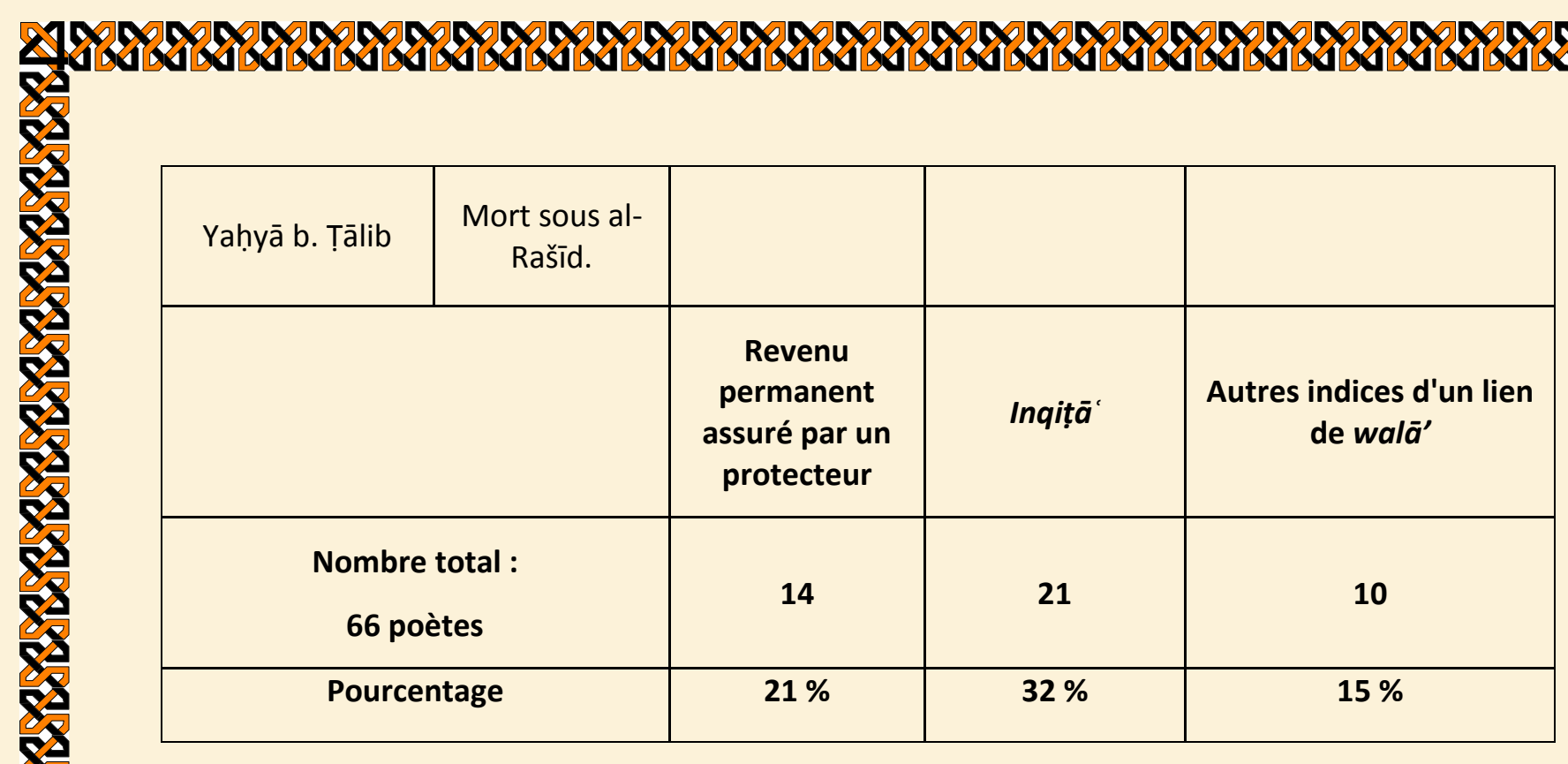

